Forthcoming in Nicola Dimitri, Gustavo Piga, and Giancarlo Spagnolo (Eds.) Handbook of Procurement, Cambridge, England: Cambridge University Press, 2006.

\title{
Dynamic Auctions in Procurement
}

\section{Lawrence M. Ausubel and Peter Cramton*}

\author{
21 February 2006
}

\begin{abstract}
We study the theory and practical implementation of dynamic procurement auctions. We consider the procurement of many related items. With many related items, price discovery is important not only to reduce the winner's curse, but more importantly, to simplify the bidder's decision problem and to facilitate the revelation of preferences in the bids. Three auction formats are considered: simultaneous descending auctions are preferred if the items are not divisible, simultaneous clock auctions are desirable for procuring many divisible goods, and the clock-proxy auction is best if complementarities among items are strong and varied across the suppliers. We examine the properties of these auctions and discuss important practical considerations in applying them.
\end{abstract}

\section{Introduction}

Procurements for many related items are commonplace. Dynamic auctions have many advantages in such environments. We consider both the purchase of many related items as well as the purchase of many divisible goods, such as energy products or environmental allowances. In such auctions, the bids specify quantities of each of the items: the megawatt-hours of electricity or the tons of emissions. Often, related goods are-or could be-auctioned at the same time. In electricity markets, products with several durations or locations may be auctioned together. In environmental auctions, emission reductions for each of several different pollutants or time periods may be bought at the same time. This article explores how procurement auctions for many divisible or indivisible goods should be conducted. Of course the answer depends on the objective of the buyer and the bidding environment. ${ }^{1}$ Here we focus on a few of the important issues of auction design in a setting where the buyer cares about some combination of efficiency (procuring the goods from the lowest-cost suppliers) and minimization of the payment for purchasing the goods. Our purpose is to motivate a sensible design in a realistic environment, rather than to prove the optimality of a particular design, which would require more restrictive assumptions than we care to make.

\footnotetext{
* Department of Economics, University of Maryland, College Park, MD 20742, USA. Authors’ websites: www.ausubel.com and www.cramton.umd.edu. This chapter is adapted from several of our papers, especially Ausubel and Cramton (2004a). Further materials on the theory and practical implementation of auctions are available on the websites of Market Design Inc. (http://www.marketdesign.com), Efficient Auctions LLC (www.efficientauctions.com) and Power Auctions LLC (http://www.powerauction.com), as well as in the recent books by Milgrom (2004) and Cramton, Shoham and Steinberg (2006). We gratefully acknowledge the support of National Science Foundation Grant SES-0531254.

${ }^{1}$ As this is a volume on procurement, we will study dynamic auctions to procure, in which the auctioneer is a buyer, the bidders are suppliers, and the price typically descends. Analogous results apply in auctions to sell (i.e., the standard auctions studied in auction theory), in which the auctioneer is a seller, the bidders are buyers, and the price typically ascends.
} 
One of the initial design decisions is whether to conduct a static (sealed-bid) or dynamic (descending-bid) auction. A frequent motivation for the use of dynamic auctions is reducing common-value uncertainty, thereby enabling bidders to bid more aggressively with less fear of the "winner's curse.” However, in the context of buying many goods, the price discovery of a dynamic auction plays another, often more important, role. By seeing tentative price information, bidders are better able to make decisions about the quantity of each good to sell. This is particularly useful because the goods being procured are related. Some may be substitutes; others may be complements in production. Bidding in the absence of price information makes the problem much more difficult for bidders. Furthermore, practical constraints can make bidding in a sealed-bid auction exceedingly difficult unless the auctioneer allows the bidders to express these constraints in their sealed bids; whereas, in a dynamic auction, the bidder can see tentative prices and assignments, allowing the bidder to make decisions that are consistent with the bidder's constraints.

The case for dynamic auctions is further strengthened when we recognize that it is costly for bidders to determine their preferences. A dynamic auction, by providing tentative price information, helps focus the bidder's decision problem. Rather than consider all possibilities from the outset, the bidder can instead focus on cases that are important given the tentative price and assignment information. Although this point is already valid in auctions for a single good (Compte and Jehiel 2002), it becomes more critical in the context of many goods, where the bidder's decision problem is much more complicated. Rather than simply decide whether to supply, the bidder must decide which goods to supply and what quantity of each. The number of possibilities grows exponentially with the number of goods. Determining costs and then bids for each of these possibilities is difficult at best; whereas, in the presence of transparent price information the decision problem becomes relatively more straightforward.

Given the increased importance of price discovery when auctioning many divisible or indivisible goods, we focus on dynamic auctions. The question then becomes: How can the auction designer best promote effective price discovery? For divisible goods, simultaneous clock auctions are both effective and simple. In a simultaneous clock auction, there is a price "clock" for each divisible good indicating its tentative price per unit quantity. Bidders express the quantities they wish to supply at the current prices. The price is decremented for goods with excess supply, and bidders again express the quantities they wish to supply at the new prices. This process repeats until supply is made equal to demand. The tentative prices and assignments then become final. For indivisible goods, the simultaneous descending auction may be preferred, especially if the number of items is large. The simultaneous descending auction is analogous to the simultaneous ascending auction used by the U.S. Federal Communications Commission and other countries for selling radio spectrum. The only difference between the simultaneous descending auction and a clock auction is that in the simultaneous descending auction, the bidders specify both a price and quantity for each item they wish to supply. In the clock format, the auctioneer names prices and the bidders only express quantities at the announced prices.

We begin with two stylized models that abstract away from many of the complicating practical details. In each, we assume that there is a continuum of bidders, so that market power considerations can be ignored. We also assume that the bidding occurs in continuous time, avoiding issues arising from discreteness. We show that the equilibrium outcome of the auction coincides with the competitive equilibrium of the model and attains full efficiency. In this sense, the simultaneous clock auction brings to life the "Walrasian auctioneer" often used to motivate the competitive equilibrium. 
We then turn to practical considerations that need to be addressed in any real-world situation.

Discrete rounds, rather than bidding in continuous time, imply that issues of bid decrements, ties, and rationing become significant. We argue that this complication is best handled by utilizing "intra-round bids," allowing bidders in each round to express their supply curves along a line segment between the starting and ending price vector for the round. Allowing a rich expression of preferences within a round makes bid decrements, ties, and rationing less important. Since preferences for intermediate prices can be expressed, the efficiency loss associated with the discrete decrement is less, so the auctioneer can choose a larger bid decrement, resulting in a faster and less costly auction process.

Natural linkages among goods often exist in practice. For example, in the case of an auction of electricity capacity, the goods may differ by the duration of the contract (e.g., three months, one year, or multiple years). Such products are natural substitutes: a two-year contract is simply a sequence of two one-year contracts. Hence, the relative prices of such products are closely related. The auction can exploit this linkage by enhancing substitution possibilities across these products.

Market power is a final practical consideration. Although some auction settings approximate the ideal of perfect competition, most do not. The auction design needs to address limited competition. Three useful instruments are information policy, reserve pricing and efficient pricing. By controlling the information that bidders receive, the auctioneer can enhance price discovery while limiting the scope for collusion. Reserve pricing serves two roles, providing price discipline in the absence of competition and discouraging collusion by limiting the maximum gain from successful collusion. Finally, since uniform pricing inevitably leads to supply reduction (Ausubel and Cramton 2002), the resulting inefficiency can be avoided by instead using the efficient pricing rule of the Ausubel (2004) auction.

We now address each of these issues in detail. Section 2 briefly outlines the simultaneous descending auction, which is suitable for the purchase of many related discrete items. The remainder of the chapter focuses on clock auctions, which are best suited for the procurement of divisible goods. Section 3 develops theoretical results in a continuous-time model with perfect competition. The chapter then turns to considerations of practical implementation, treating discrete rounds (Section 4), natural linkages among goods (Section 5) and limited competition (Section 6). Finally in Section 7 we describe the clock-proxy auction, which is a practical method for procuring many related goods in a package auction.

\section{Simultaneous descending auction}

One of the most successful methods for auctioning many related items is the simultaneous ascending auction — and its counterpart for procurement, the simultaneous descending auction. This auction form was first developed for the U.S. Federal Communications Commission’s spectrum auctions, beginning in July 1994, and has subsequently been adopted with slight variation for dozens of spectrum auctions worldwide, resulting in revenues in excess of $\$ 200$ billion. The method, first proposed by Paul Milgrom, Robert Wilson and Preston McAfee, has been refined with experience, and extended to the sale or purchase of divisible goods in electricity, gas, and environmental markets. Here we describe the method and its extensions. 
The simultaneous descending auction is a natural generalization of the English auction when procuring many goods. The key features are that all the goods are purchased at the same time, each with a price associated with it, and the bidders can bid on any of the items. The bidding continues until no bidder is willing to reduce the price on any of the items. Then the auction ends with each bidder supplying the items on which it has the low bid, and is paid its bid for any items supplied.

The reason for the success of this simple procedure is the excellent price discovery it affords. As the auction progresses, bidders see the tentative price information and condition their subsequent bids on this new information. Over the course of the auction, bidders are able to develop a sense of what the final prices are likely to be, and can adjust their purchases in response to this price information. To the extent price information is sufficiently good and the bidders retain sufficient flexibility to shift toward their best package, the exposure problem ${ }^{2}$ is mitigated—bidders are able to piece together a desirable package of items, despite the constraint of bidding on individual items rather than packages. Moreover, the price information helps the bidders focus their efforts on estimating their production costs only in the relevant region of the price space.

To further mitigate the exposure problem, most simultaneous descending auctions allow bidders to withdraw bids. This enables bidders to back out of failed aggregations, shifting bids to more fruitful packages. However, we find that bid withdrawals often facilitate undesirable gaming behavior, and thus the ability to withdraw bids needs to be constrained carefully. It is our view that price discovery—not bid withdrawal—is the more effective limit on the exposure problem in simultaneous descending auctions.

There is substantial evidence that the simultaneous ascending auction design has been successful. Cramton (1997) provides a detailed examination of the early FCC spectrum auctions. The auction format performed well on both revenue and efficiency grounds. Although there is less experience with the simultaneous descending auction in procurement, the limited evidence that we do have is promising, and there is no reason to think that the positive results for auctions to sell would not carry over to the procurement context. By revealing information in the auction process, bidder uncertainty is reduced, and the bidders safely can bid more aggressively. Also, costs may decrease to the extent the design enables bidders to piece together packages of items that they can more efficiently supply.

Despite the general success, the simultaneous descending auctions have experienced a few problems from which one can draw important lessons. One basic problem is the simultaneous descending auction's vulnerability to cost-increasing strategies in situations where competition is weak. Bidders have an incentive to reduce their supply in order to keep prices high, and to use bid signaling strategies to coordinate on a split of the items.

\footnotetext{
${ }^{2}$ The exposure problem is the problem of winning some—but not all—of a complementary collection of items in an auction without package bids. The bidder is "exposed" to a possible loss if his bids include synergistic gains that might not be achieved.
} 
We begin by motivating the design choices in a simultaneous descending auction. Then we describe typical rules, including many important details.

\subsection{Auction design}

The critical elements of the simultaneous descending auction are (1) open bidding, (2) simultaneous purchase, and (3) no package bids. These features create a Walrasian tatonnement process that yields a competitive equilibrium provided (1) items are substitutes, (2) bidders are price takers, and (3) bid increments are negligible (see Milgrom 2004, as well as the next section of this chapter). Of course, these conditions do not hold in practice. Some degree of market power is common, at least some items are complements, and bid decrements in the 5 to 10 percent range are required to get the auction to conclude in a manageable number of rounds.

Still the simultaneous descending auction does perform well in practice largely because of the benefits of price discovery that come from open bidding and simultaneous sale. These benefits take two forms. First, in situations where bidder costs are affiliated, price discovery may mitigate the winner's curse and thereby reduce procurement costs (Milgrom and Weber 1982). Bidders are able to bid more aggressively, since they have better information about the item's value. More importantly, when many items are purchased, the price discovery lets bidders adapt their bidding and analysis to the price information, which facilitates the aggregation of a complementary package of items to supply.

The alternative of sequential auctions has the effect of limiting the information that is available to bidders and of limiting how bidders can respond to information. With sequential auctions, bidders must guess what prices will be in future auctions when determining bids in the current auction. Incorrect guesses may result in an inefficient assignment when item costs are interdependent. A sequential auction also eliminates many strategies. A bidder cannot switch back to an earlier item if prices fall too low in a later auction. Bidders are likely to regret having sold early at low prices, or not having sold early at high prices. The guesswork about future auction outcomes makes strategies in sequential auctions complex, and the outcomes less efficient.

Almost all the simultaneous descending auctions conducted to date do not allow package bids. Bids are only for individual items. The main advantages of this approach are simplicity and linear prices. The auction is easily implemented and understood. The disadvantage is the exposure problem. With individual bids, bidding for a synergistic combination is risky. The bidder may fail to supply key pieces of the desired combination, but receive payment based on the synergistic reduction in costs. Alternatively, the bidder may be forced to bid below its costs in order to secure the synergies and reduce its loss from being stuck with costly individual items. Individual bidding exposes bidders seeking synergistic combinations to aggregation risk.

Not allowing package bids can create inefficiencies. For example, suppose there are two bidders to supply two items, which the buyer values at $\$ 150$ for the two items together. One supplier has a technology which can 
produce both items for a cost of $\$ 100$, but cannot produce a single item. Thus, it costs her $\$ 100$ to supply both items, and it also costs $\$ 100$ to supply just one; the items are perfect complements. The second supplier uses a different technology, which allows her to supply either item, but only one item at a cost of $\$ 25$; the items are perfect substitutes. Note that the efficient outcome is for the first bidder to supply both items at a total cost of $\$ 100$. Yet any attempt by the first bidder to supply both is foolhardy. The first bidder would have to drop its bid to $\$ 25$ on each item in order to be selected to supply both, but then the bidder would be paid only $\$ 50$ and have costs of $\$ 100$. The only equilibrium is for the second bidder to provide a single item at the opening price. The outcome is inefficient, and fails to procure the required items.

This example is extreme to illustrate the exposure problem. The inefficiency involves large bidderspecific complementarities and a lack of competition.

Unfortunately, allowing package bids creates other problems. Package bids may favor large suppliers due to a variant of the threshold problem. Continuing with the last example, suppose that there is a third bidder who has a cost of $\$ 60$ to supply either item. Then the efficient outcome is for the individual bidders to provide both items, resulting in total costs of $25+60=\$ 85<\$ 100$. But this outcome may not occur when costs are privately known. Suppose that the second and third bidders have placed individual bids of $\$ 65$ on each of the two items, but these bids are beaten by a package bid of $\$ 110$ from the first bidder. Each bidder hopes that the other will bid lower to beat the package bid. A reduction of at least $\$ 20$ is required from the individual bidders. However, the second bidder has an incentive to overstate her costs. She may refrain from bidding, counting on the third bidder to break the threshold of $\$ 110$. But the third bidder cannot come through, so the auction ends with the first bidder supplying both items for $\$ 110$.

Package bidding also adds complexity. Unless the complementarities are large and heterogeneous across bidders, a simultaneous descending auction without package bids may be preferred.

\subsection{Typical rules}

The simultaneous descending auction works as follows (see Cramton 2006 for details). A group of items with strong cost interdependencies are up for auction at one time. A bidder can bid on any collection of items in any round, subject to an activity rule which determines the bidder's current eligibility. The auction ends when a round passes with no new bids on any item. This auction form was thought to give the bidders flexibility in expressing costs and building packages of items. Common rules are described below.

Quantity Cap. To promote competition in the supply chain, a bidder often is limited in the quantity it can supply.

Payment Rules. Often suppliers will be required to post a bid bond, or pass some credit review process. The bid bond and credit review typically defines the bidder's maximum eligibility. A bidder interested in 
supplying a large quantity of items would have to post a large bid bond. The bid bond provides some assurance that the bids are serious. Suppliers are paid at the time of delivery.

Minimum Bid Decrements. To assure that the auction concludes in a reasonable amount of time, minimum bid decrements are specified. Bid decrements are adjusted in response to bidder behavior. Typically, the bid decrements are between 5 and 20 percent.

Activity Rule. The activity rule is a device for improving price discovery. It forces a bidder to maintain a minimum level of activity to preserve its current eligibility. As the auction progresses, the activity requirement increases, reducing a bidder's flexibility. The lower activity requirement early in the auction gives the bidder greater flexibility in shifting among packages early on when there is the most uncertainty about what will be obtainable.

Number of Rounds per Day. A final means of controlling the pace of the auction is the number of rounds per day. Typically, fewer rounds per day are conducted early in the auction when the most learning occurs. In the later rounds, there is much less bidding activity, and the rounds can occur more quickly.

Stopping Rule. A simultaneous stopping rule is used to give the bidders maximum flexibility in pursuing backup strategies. The auction ends if a single round passes in which no new bids are submitted on any item.

Bid Information. The most common implementation is full transparency. Each bidder is fully informed about the identities of the bidders and the eligibility of each bidder. Low bids and bidder identities are posted after each round. In addition, all bids and bidder identities are displayed at the conclusion of each round, together with each bidder's eligibility.

Bid Withdrawal. To limit the exposure problem, the low bidders can withdraw their bids subject to a bid withdrawal penalty. If a bidder withdraws its low bid, the auctioneer is listed as the low bidder and the maximum bid is the second-lowest bid for that item. The second-lowest bidder is in no way responsible for the bid, since this bidder may have moved on to other items. If no firm bids on the item, the auctioneer can increase the maximum bid. To discourage insincere bidding, there are penalties for withdrawing a low bid. The penalty is the larger of 0 and the difference between the final purchase price and the withdrawn bid. This penalty is consistent with the standard remedy for breach of contract. The penalty equals the damage suffered by the buyer as a result of the withdrawal.

We now turn to the clock format for procuring divisible goods.

\section{Procuring many divisible goods in the absence of market power}

In this section, we specify two economic models in which the simultaneous clock auction can be shown to yield desirable outcomes. The final prices of the auction correspond to the competitive equilibria of the models, and the allocations are therefore efficient. The models abstract from reality in their use of a continuum of bidders 
(justifying price-taking behavior) and continuous time (allowing the price adjustment processes to converge perfectly).

A buyer wishes to procure units of each of $K$ different goods from a continuum of bidders. The bidders are subscripted by $i(i \in[0,1])$. Each bidder $i$ 's set, $S_{i}$, of possible vectors of goods that it can supply is assumed to be a compact, convex subset of $\mathbb{R}_{+}^{K}$, and bidder $i$ 's supply vector is $s_{i}=\left(s_{i}^{1}, \ldots, s_{i}^{K}\right) \in S_{i}$. The demand (i.e., the quantity that needs to be procured) is $D=\left(D^{1}, \ldots, D^{K}\right) \in \mathbb{R}_{++}^{K}$.

In Model I, we assume: ${ }^{3}$

(A1) Pure private costs: Bidder $i$ 's cost, $C_{i}\left(s_{i}\right)$, of providing the supply vector $s_{i}$ does not change when bidder $i$ learns other bidders' information.

(A2) Quasilinearity: Bidder $i$ 's payoff from providing the supply vector $s_{i}$ in return for the payment $y_{i}$ is given by $y_{i}-C_{i}\left(s_{i}\right)$.

(A3) Monotonicity: The function $C_{i}: S_{i} \rightarrow \mathbb{R}$ is increasing.

(A4) Strict convexity: The function $C_{i}: S_{i} \rightarrow \mathbb{R}$ is strictly convex.

The price vector is denoted by $p=\left(p^{1}, \ldots, p^{K}\right) \in \mathbb{R}_{+}^{K}$. If each bidder $i$ supplies $s_{i}(p)$ at price vector $p$, the aggregate supply is given by $\int_{0}^{1} s_{i}(p) d i$. The excess supply, $z(p)$, equals the difference between the aggregate supply and the buyer's demand: $z(p)=-D+\int_{0}^{1} s_{i}(p) d i$. In Walrasian tâtonnement (Walras 1874, as formalized by Samuelson 1941), the price vector is decremented in continuous time according to excess supply: $\dot{p}(t)=-f(z(p(t)))$, where $f(\bullet)$ is a continuous, sign-preserving transformation. The price vector $p$ and the associated supplies form a competitive equilibrium if the excess supply equals zero for every good.

The following auction procedure is followed:

- The auctioneer announces a price vector $p$;

- $\quad$ Bidders report supplies $s_{i}(p)$;

- The auctioneer adjusts the price vector according to Walrasian tâtonnement; and

- The process repeats until the price vector converges.

We have the following result for Model I:

THEOREM 1. In Model I, sincere bidding by the bidders is an equilibrium of the auction game and, starting from any price vector, the outcome converges to the competitive equilibrium.

PROOF. A standard global stability argument (see, for example, Varian 1981). Let $V_{i}(\bullet)$ denote bidder $i$ 's indirect payoff function: $V_{i}(p)=\max _{s_{i} \in S_{i}}\left\{p \cdot s_{i}-C_{i}\left(s_{i}\right)\right\}$. Define the following Lyapunov function:

\footnotetext{
${ }^{3}$ In addition, we assume away any arcane difficulties that would unnecessarily complicate the analysis. In particular, we assume that the bidders' supplies, $s_{i}(p)$, are measurable with respect to $i$. This is easily justified if the continuum of bidders consists of a finite collection of subintervals of bidders and, within each subinterval, the bidders are identical. It is also assumed that the sets of the bidders' possible supplies and the demand $D$ are such that there exists a feasible way to procure $D$ from the bidders.
} 
$V(p)=-p \cdot D+\int_{0}^{1} V_{i}(p) d i$. Then: $\dot{V}(t)=\left(-D+\int_{0}^{1} s_{i}(p(t)) d i\right) \cdot \dot{p}(t) \leq 0$, and $V(\bullet)$ is minimized at the competitive equilibrium.

Furthermore, with slightly stronger assumptions, the price adjustment is everywhere decreasing:

COROLLARY 1. In Model I, if goods are substitutes in the aggregate, then sincere bidding by the bidders is an equilibrium of the auction game and, starting from any sufficiently large price vector, the price descends monotonically to the unique competitive equilibrium.

It is not necessary for the goods to be substitutes, in order for a simultaneous clock auction to yield the desired outcome. Indeed, in the second model developed, the goods can be supplied in fixed coefficients-a most extreme form of complements. This result may appear counterintuitive in view of the literature on the Walrasian tâtonnement process. However, it should be emphasized that this traditional price adjustment literature proceeds with one hand tied behind its back; the adjustment process is restricted to depend only on the excess demand or excess supply function, that is, to take a form that is economically plausible in the absence of any auctioneer. By contrast, for current purposes, there is assumed to be a real auctioneer, who we allow to exploit any information generated by the auction process (e.g., the gradient of the excess demand or excess supply function) to facilitate convergence.

In Model II, we will again posit a continuum of bidders and we will require that a unique competitive equilibrium exists. This time, we make assumptions on the aggregate supply function $s(\cdot)$ (as a function of $p$ ), instead of directly on the primitives of the model. We assume (A1) and:

(A2') Continuous Differentiability: The aggregate supply function, $s(\cdot)$, is continuously differentiable at all $p \in \mathbb{R}^{K}$; and

(A3') For every subset, $J$, of the set of all goods, and for every $p \in \mathbb{R}_{+}^{K}$, there exists

$$
\begin{aligned}
& \alpha(p) \in \mathbb{R}^{K} \text { such that, if } \dot{p}=\alpha(p) \text { : } \\
& \qquad \dot{s}^{j}(p)=0 \text {, for all } j \in J \text {, but } \dot{s}^{k}(p) \leq-1 \text {, for all } k \in K \backslash J .
\end{aligned}
$$

Assumption (A3') states that there is always a direction in which one can adjust price such that specified components of aggregate supply remain constant while the remaining components decrease at a rate bounded away from zero. An example of a model that satisfies these conditions is a model where $K=2$ and each of the bidders has Leontief (i.e., fixed coefficient) preferences, and where the fixed coefficients for providing the two goods are in different ratios for different bidders. In such a model, it will generally be possible to raise the price of one good while lowering the price of the other good in such a way that the aggregate supply for the first good is constant but the aggregate supply for the second good decreases.

An auction procedure similar to that used for Model I may be followed, except that a different price adjustment process is used. We have the following result for Model II:

THEOREM 2. In Model II, with an appropriate price adjustment process, sincere bidding by the bidders is an equilibrium of the auction game and, starting from any price vector with positive excess supply for every good, the outcome converges to the competitive equilibrium.

PROOF. Begin by decreasing the price of every good until some good clears. Inductively, let $J$ denote the set of goods that have already cleared. Then adjust the prices so that the aggregate supplies of all goods in $J$ 
remain constant, while the aggregate supplies of all goods in $K \backslash J$ decrease. Assumption (A3') guarantees that it is always possible to adjust prices in this way, decreasing the excess supply of all goods that have not yet cleared while maintaining market clearance for all goods that have already cleared. In finite time, some good $k \in K / J$ will clear. Set $J$ is then redefined to include good $k$, and the process is repeated. Clearly, all goods will clear in finite time.

REMARK. The adjustment process used in the proof of Theorem 2 is a simple version of the "sign process" of Laan and Talman (1987). More complicated complements preferences can also be accommodated within their adjustment process.

\section{Accommodating discrete rounds with intra-round bidding}

Although in theory one can imagine implementing a descending clock auction in continuous time, this is hardly ever done in practice. Clock auctions inevitably use discrete rounds for two important reasons. First, communication is rarely so reliable that bidders would be willing to be exposed to a continuous clock. A bidder would find it unsatisfactory if the price clock swept past the bidder's willingness to provide the good because of a brief communication glitch. Discrete rounds are robust to communication problems. Discrete rounds have a bidding window of significant duration, rarely less than ten minutes and sometimes more than one hour. This window gives bidders time to correct any communication problems, to resort to back-up systems, or to contact the auctioneer and have the round extended. Second, a discrete round auction improves price discovery by giving the bidders an opportunity to reflect between rounds. Bidders need time to incorporate information from prior rounds into a revised bidding strategy. This updating is precisely the source of price discovery and its associated benefits.

An important issue in discrete-round auctions is the size of the bid decrements. Larger bid decrements enable the auction to conclude in fewer rounds, but they potentially introduce inefficiency from the use of a coarse price grid. Large decrements also introduce incentives for gaming as a result of the expanded importance of ties and rationing rules. But using small decrements especially in an auction with many clocks can greatly increase the number of rounds and, hence, the time required to complete the auction. Bidders generally prefer a shorter auction. A short auction reduces participation costs. A short auction also reduces exposure to price movements during the auction. This is especially relevant in securities and energy auctions for which there are active secondary markets in close substitutes, and for which underlying price movements could easily exceed the price decrements.

Fortunately it is possible to capture nearly all of the benefits of a continuous auction and still conduct the auction in a limited number of rounds, using the technique of intra-round bids. ${ }^{4}$ With intra-round bids, bidders express their supply in each auction round at all price vectors along the line segment from the start-of-round price to the end-of-round price. In a traditional clock auction, price may decrease from say \$11 to \$10 in a round, but the bidder is only able to express the quantity it wishes to provide at $\$ 11$ and at $\$ 10$. With intraround bids, the bidder expresses the quantity it wishes to provide at all prices between $\$ 11$ and $\$ 10$. This avoids the inefficiency associated with a coarser price grid. It also avoids the gaming behavior that arises from

\footnotetext{
${ }^{4}$ Intra-round bidding, activity rules, indifference tables, and other aspects of the practical implementation of clock auctions are described in greater detail in Ausubel, Cramton and Jones (2002).
} 
the increased importance of ties and rationing with coarser prices. The only thing that is lost is the withinround price discovery. However, within-round price discovery is much less important than the price discovery that occurs between rounds.

More specifically, with intra-round bids, in each round, the auctioneer announces a start-of-round price and a (lower) end-of-round price. Each bidder then expresses its supply curve for all prices between the startof-round price and the end-of-round price. Supply curves are constrained to be increasing step functions: as the price falls, a bidder can maintain or decrease the quantity; the quantity cannot increase in response to lower prices. In every round, the bidder names the prices between the start-of-round and end-of-round prices at which it wishes to reduce its quantity. For example consider an energy auction where quantity is measured in megawatts (MW). Let $\$ 11.00$ be the start-of-round price and $\$ 10.00$ be the end-of-round price in round 6 . Suppose the bidder's quantity at $\$ 11.00$ is $800 \mathrm{MW}$, and the bidder wishes to reduce quantity to $600 \mathrm{MW}$ at $\$ 10.63$ and to $350 \mathrm{MW}$ at $\$ 10.17$. Then the bidder's bid consists of two price-quantity pairs: $\mathbf{( \$ 1 0 . 6 3 , 6 0 0}$ MW) and (\$10.17, $350 \mathrm{MW}$ ) as shown in Figure 1. The bidder is offering the quantity of $800 \mathrm{MW}$ for prices from $\$ 11.00$ to $\$ 10.63,600 \mathrm{MW}$ for prices from $\$ 10.63$ to $\$ 10.17$, and $350 \mathrm{MW}$ from $\$ 10.17$ to $\$ 10.00$. At each step, we assume that the bidder is indifferent among all quantities between the two end points. Thus, at \$10.17, the bidder's bid is satisfied by any quantity between $350 \mathrm{MW}$ and $600 \mathrm{MW}$.

Figure 1. Individual Supply Bid, Round 6

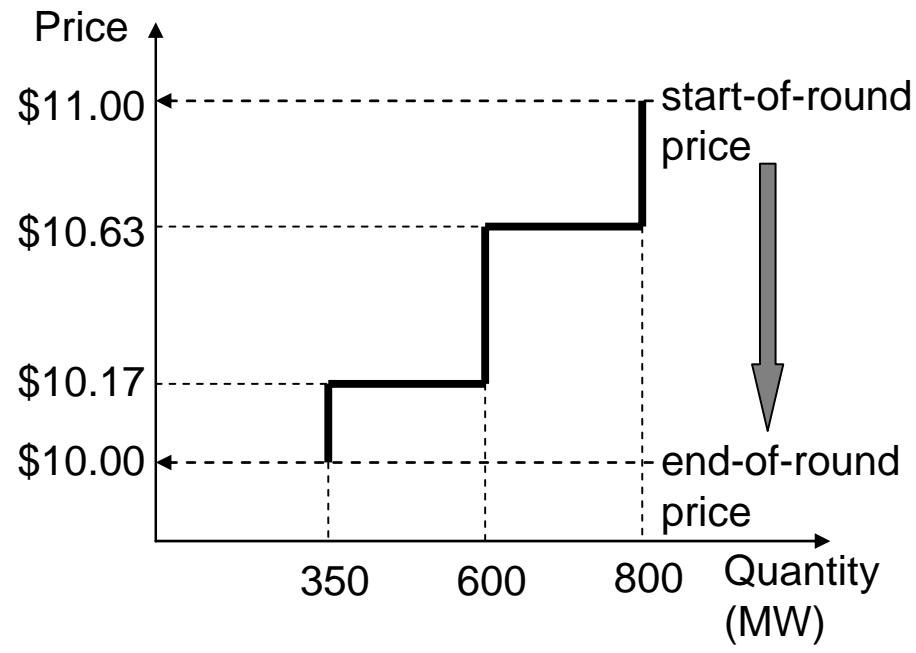

At the end of the round, the auctioneer forms the aggregate supply curve from the individual bids. Then, if there is excess supply at the end-of-round price, the auctioneer reports the excess supply at the end-of-round price and a new round begins. Otherwise, the auctioneer reports the clearing price and each bidder is informed of the quantity it is obligated to provide. 


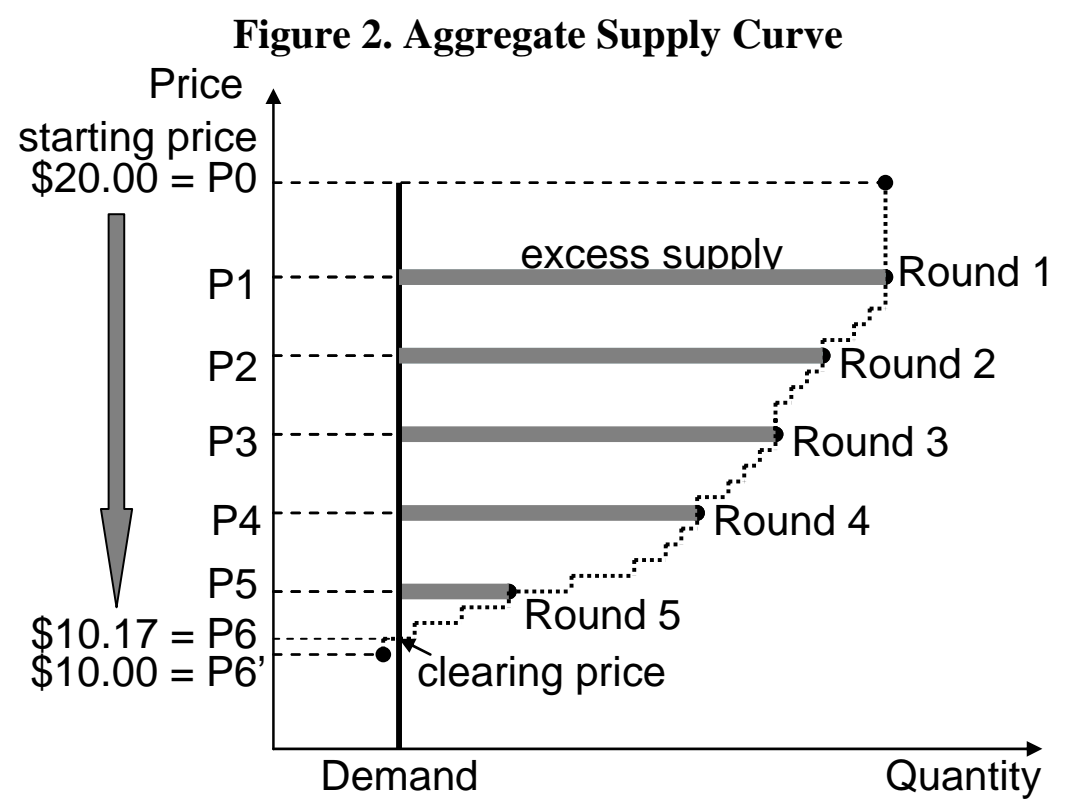

Figure 2 shows a sample auction, which lasts six rounds. The auction begins with a starting price P0 = $\$ 20.00$. At the end of round 1 , no bidder reduced quantity, so the aggregate supply curve is vertical between P0 and P1. At P1, there is substantial excess supply indicated by the distance between the vertical demand curve and the aggregate supply curve. In each subsequent round, one or more bidders reduces quantity at prices between the start-of-round price and the end-of-round price, and the excess supply shrinks. As a result of the intra-round bidding, the reductions are at numerous prices and are small relative to the total demand. In round 6, the tentative end-of-round price is $\mathrm{P}^{\prime}{ }^{\prime}=\$ 10.00$, but at this price, demand exceeds supply. Thus, the auctioneer backs up to the price P6 $=\$ 10.17$ at which supply and demand intersect. The auctioneer reports that the auction concluded at the clearing price P6 $=\$ 10.17$.

The experience from a number of high-stakes clock auctions indicates that intra-round bidding enables the auctioneer to conduct auctions with ten or more products in about ten rounds, with little or no loss from the discreteness of rounds. These auctions can be completed in a single day. By way of contrast, early spectrum auctions and some electricity auctions without intra-round bids took weeks or even months to conclude. In a few extreme instances, the longer duration was warranted due to the enormous uncertainty and extremely high stakes, but generally speaking, intra-round bids would have reduced the bidding costs without any meaningful loss in price discovery.

\section{Exploiting the natural linkages among goods}

The motivation for auctioning many products together is that the products are related. The bidders may view some of the goods as substitutes and others as complements. At the same time, there may be substitution possibilities as to what is procured in the auction. Given the natural linkages among goods, a second important issue in the implementation of a simultaneous clock auction is the amount of flexibility given to bidders in switching across products and to the buyer in the determination of supply. 


\subsection{Bidder flexibility}

To promote price discovery, activity rules are generally imposed in clock auctions. The simplest clock auction is for a single homogeneous good. There, the activity rule takes the simple form of a monotonicity constraint: each bidder's quantity supplied is not permitted to increase as the price decreases, consistent with upward-sloping supply curves. Without the monotonicity constraint, a bidder might bid as a "snake in the grass”-grossly understating supply at high prices and then jumping in with large supply near the end of the auction. Widespread use of a snake-in-the-grass strategy would undermine the very purpose of utilizing a dynamic auction. ${ }^{5}$ A monotonicity constraint prevents this form of strategic behavior, thus encouraging better price discovery and facilitating rapid convergence to equilibrium.

In situations with multiple goods that have relatively independent supply curves, a monotonicity constraint may be applied independently to each good. However, in situations where the interdependencies across goods are substantial, applying monotonicity constraints independently to each good may be overly restrictive. For example, if two products are close substitutes, it is natural for the bidder to supply the product with the more attractive price. Thus, the bidder may want to decrease the quantity she bids on the product with a faster falling price, and increase her quantity on the product with a slower falling price. Such bids would be excluded by the simplest application of monotonicity constraints.

In some applications, identifying and exploiting the natural linkages among goods may resolve these issues. Goods are organized into product groups. Substitute goods are assigned to the same group; while complementary goods are assigned to different groups. The activity rule is crafted to permit bidders to freely substitute among goods contained in the same product group. However, monotonicity is applied independently across groups, so that no substitution is permitted between products in different groups.

The quarterly Electricité de France (EDF) Generation Capacity Auctions, the first practical implementation of simultaneous clock auctions, has successfully taken this approach. Broadly speaking, two types of goods are offered: baseload capacity contracts; and peakload capacity contracts. These goods would be expected to be complements, since a new entrant in the French electricity market can best meet the needs of customers with a particular combination of baseload and peakload capacity. However, baseload and peakload capacity are each offered in multiple durations — three-month, six-month, one-year, two-year and three-year contracts, with the same starting date-and the various durations of the same type of contract are close substitutes. Consequently, the goods are organized into two product groups, each containing five products. Since the goods within a group are denominated in comparable units (MW of power), the activity rule applied to all products within a group is simply a monotonicity constraint on the sum of the respective supply curves. ${ }^{6}$

\footnotetext{
${ }^{5}$ One motivation for a bidder to use a "snake-in-the-grass" strategy is to avoid conveying information to rivals in an environment where bidders exhibit interdependent costs. If each bidder's estimate of cost is based in part on rivals' information, one bidder demanding large quantities might induce her rivals to reduce their cost estimates and bid more aggressively. A second motivation for a bidder to use a snake-in-the-grass strategy arises from bidders' limited capacities to provide items. The bidder holds back on bidding for the good she wants most to provide, instead bidding for the goods her rivals want to provide, in the hopes of exhausting the competitors' limited capacities. The bidder then shifts to bidding on her true interests late in the auction, now facing weakened competition for providing these goods.

${ }^{6}$ As many as five product groups have been offered in some of the EDF auctions. An additional Power Purchase Agreement product has sometimes been offered, in addition to the basic baseload and peakload product. Moreover, in
} 


\subsection{Supply flexibility}

In many applications, the evident substitutability of goods makes it desirable to give flexibility to the buyer, as well as to bidders. For example, financial securities may be bought in a variety of durations, but the only real constraint on the buyer is that the total quantity bought must equal the buyer's total demand. Or energy products may be offered with a variety of delivery locations, but the principal requirement is again on the total quantity bought. The objectives of efficiency and revenue maximization are both served by allowing "the market to decide" the demand of each of the substitute products to be procured.

Again, the EDF auctions have successfully taken this approach. As described in Section 4.1, both baseload and peak capacity are offered in many durations. EDF recognized that different bidders would prefer different durations, but EDF did not have a reliable method for predicting the demands for the various durations other than through the auction itself. By way of contrast, EDF had excellent information about its own willingness to substitute quantities among durations, as a function of price.

Observe that, if both the supplies and the relative prices of the various durations were allowed to be determined endogenously, then the entire system would be underdetermined. Since the supplies were intended to be market driven and since the buyer's tradeoffs on price were well understood, the decision was made that the prices of the various products within a group would be linked together and would decrease in lockstep. (However, the prices associated with different product groups move independently of one another.) Before the start of the auction, the buyer determines an indifference table expressing the price differentials (i.e., a yield curve) amongst the various products within a group that would make the buyer indifferent between obtaining one product or another. With two product groups containing five products each, there are effectively just two clocks (baseload and peak), although ten prices, with the prices for each product group determined by the clock and the indifference table. The clearing condition is that the aggregate supply for each product group is no greater than the total demand. The bidders then determine endogenously the division of purchases across the various durations, contributing both to efficiency and to revenue maximization.

\section{Addressing limited competition}

In most auctions, competition is limited. Either the number of bidders is small or some bidders are significant in size relative to the auction volume. In these auctions, the auction designer needs to address the potential exercise of market power in the auction design. Three of the most important instruments available to the auction designer are: the information policy, the use of reserves, and the pricing rule.

\subsection{Information policy}

In a competitive auction, price is used to resolve the assignment problem. Those bidders willing to provide at lower cost, get to provide more. However, when there is a lack of competition, a major concern is that bidders will agree on a division of the goods by means other than the auction price.

Most spectrum auctions have used a fully transparent simultaneous ascending auction, in which the complete history of bids (including the identities of the bidders making the bids) has been reported after every

some of the auctions, contracts with different starting dates have been offered as separate product groups. For further information, see EDF's website (www.edf.fr) and the sources listed in the introductory footnotes. 
round. This has enabled bidders to adopt collusive strategies in spectrum auctions where competition was especially weak (Cramton and Schwartz 2002, Brusco and Lopomo 2002, Grimm, Riedel and Wolfstetter 2002).

In clock auctions, a useful information policy for mitigating collusive possibilities is to report only the aggregate supply for the goods after each round. In many situations, the aggregate supply contains most of the information needed for price discovery. If, instead, the auctioneer revealed the individual supply curves of the bidders, this detailed information could be used to facilitate a coordinated reduction of supply at high prices. For example, the bidders might cooperatively reciprocate the quantity reductions of competitors, and punish those who do not reciprocate by shifting quantity toward products that the non-reciprocating bidder wishes to provide. In order to avoid such possibilities, in all real-world clock auctions of which we are aware, the auctioneer has reported only end-of-round aggregate demand or supply, and not the individual demands or supplies of bidders.

\subsection{Reserve pricing}

A reserve price is a second important instrument to address limited competition. It does this in two ways. First, it reduces the incentive for collusion by limiting the maximum gain from collusion. Bidders must provide the good at no higher than the reserve price no matter how effective their collusion. Second, the reserve price guarantees that the price paid by the buyer is not unreasonably high, even when competition is weak. Reserve prices are easily implemented in clock auctions. Most commonly, the initial clock price serves as a reserve. Bidders are not permitted to express supply at prices above the reserve.

Alternatively, the auctioneer can start the auction at a high price but apply a secret reserve. A given product does not clear until the supply is less than or equal to the demand and the reserve price (which is not announced) is met. This approach was applied successfully in the September 2003 EDF auction.

More generally, the buyer may wish to adjust demand in response to bids (Ausubel and Cramton 2004b; McAdams 2005). In a clock auction, a demand adjustment is most easily accomplished by specifying an explicit downward-sloping demand curve. This has the effect of expanding the quantity demanded when there is ample competition, but reducing the quantity demanded (and implicitly introducing a reserve-like mechanism) when there is insufficient competition.

\subsection{Efficient pricing}

The pricing rule is a final instrument to address market power. Most auctions for divisible goods use uniform pricing: all units of a given product are bought at the same market-clearing price. The difficulty with this pricing rule is that it creates the incentive for bidders to engage in supply reduction-bidding a quantity less than true supply at every price (Ausubel and Cramton 2002). Moreover, the supply-reduction incentive increases in the quantity supplied: larger bidders shade more and smaller bidders shade less. This differential shading creates an inefficiency in which small bidders supply too much and large bidders supply too little.

This inefficiency can be completely avoided in a clock auction by making a simple change in the pricing rule, as proposed by Ausubel (2004, 2006). For homogeneous goods, each unit is procured at the price at which it is "clinched," that is, at the point where it becomes mathematically impossible for the bidder not to be selected to provide the unit. For example, suppose that there are four identical items and three bidders, each 
offering to supply two units. If one bidder reduces its quantity bid from two units to one, then each of the other two bidders "clinches" one unit at the current clock price. The clock continues to descend in order to determine the allocation and price of the remaining two units. Under this modified rule, the clock auction yields the same pricing as in the (sealed-bid) Vickrey auction (Vickrey 1961). Bidders now have an incentive to bid their true supply curves and an efficient allocation is obtained.

Although the Ausubel auction eliminates the assignment inefficiency created by supply reduction, it does not solve the revenue problems stemming from market power. Under either uniform or Vickrey pricing, bidders pay less when there is less competition. Hence, the other tools-information policy and reserve pricing — need to be used in combination with Vickrey pricing to address the revenue problems created by limited competition.

\section{Clock-proxy auction}

In settings where complementarities are both strong and varied across bidders, package bids are needed to improve the efficiency of the auction mechanism. In this section we describe the clock-proxy auction of Ausubel, Cramton and Milgrom (2006) as a practical package auction. A typical application is a procurement in which different bidders combine items in different ways. Some pairs of items may be substitutes and others may be complements. Indeed, a given pair of items may be substitutes for one bidder but complements for another, and may change between substitutes and complements for a single bidder as the prices of the other items change. The method combines two auction formats- the clock auction and the proxy auction-to produce a hybrid with the benefits of both.

The clock auction is just as described earlier: an iterative auction procedure in which the auctioneer announces prices, one for each of the items being procured. The bidders then indicate the quantities of each item that they wish to provide at the current prices. Prices for items with excess supply then decrease, and the bidders again express quantities at the new prices. This process is repeated until there are no items with excess supply.

The descending proxy auction is a particular package bidding procedure with desirable properties (see Ausubel and Milgrom 2002, 2006a). In the procurement context, the bidders report their true costs to their respective proxy agents. The proxy agents iteratively submit package bids on behalf of the bidders, selecting the best profit opportunity for a bidder given the bidder's inputted costs. The auctioneer then selects the provisionally winning bids that minimize costs. This process continues until the proxy agents have no new bids to submit.

The clock-proxy auction is a hybrid auction format that begins with a clock phase and ends with a final proxy round. First, bidders directly submit bids in a clock auction, until there is no excess demand for any item. Then bidders have a single opportunity to input proxy values. The proxy round concludes the auction. All bids are kept live throughout the auction. There are no bid withdrawals. The bids of a particular bidder are 
mutually exclusive. There is an activity rule throughout the clock phase and between the clock phase and the proxy round.

There are three principal motivations behind the clock-proxy auction. First, Porter et al. (2003) describe a particular version of a "combinatorial” clock auction, and they provide experimental evidence in its support. Second, the recent innovation of the proxy auction provides a combinatorial auction format suitable for related items. Unlike pure clock auctions, whose anonymous linear prices are not generally rich enough to yield efficient outcomes even with straightforward bidding, the proxy auction leads to efficient outcomes and it yields competitive revenues when bidding is straightforward. It also has some desirable individual and group incentive properties. However, the theoretical development of the proxy auction treats only a sealed-bid procedure, omitting opportunities for bidder feedback and price discovery. Third, the empirical success of the simultaneous clock auction in the field suggests that the clock phase would be a simple and effective device for providing essential price discovery in advance of a final proxy round. During the clock phase, bidders learn approximate prices for individual items as well as packages (summing the individual prices). This price information helps bidders focus their cost analysis on packages that are most relevant.

The clock-proxy auction has important advantages over the simultaneous descending auction described earlier. The simultaneous descending auction performs well when items are substitutes and competition is strong. The clock phase by itself also does well in this simple setting and, in particular, the outcome is similar to that of a simultaneous descending auction. However, the addition of the proxy auction round should be expected to handle complications, such as complements, collusion, and market power, much better than the simultaneous descending auction. In environments where such complications are present, the clock-proxy auction is likely to outperform the simultaneous descending auction both on efficiency and procurement cost.

\subsection{Proxy phase}

Since the clock phase has already been described at length, it remains to describe the proxy phase. Like the clock auction, the proxy auction is based on package bids. However, the incentives are quite different. The main difference is the absence of anonymous linear prices on individual items. Only packages are priced-and the prices may be bidder specific. This weakens price discovery, but the proxy phase is not about price discovery. It is about providing the incentives for efficient assignment. All the price discovery occurs in the clock phase. The second main difference is that the bidders do not bid directly in the proxy phase. Rather, they submit costs to the proxy agents, who then bid on their behalf using a specific bidding rule. The proxy agents bid straightforwardly to maximize profits. The proxy phase is a last-and-final opportunity to bid.

The proxy auction works as follows (see Ausubel and Milgrom 2002, 2006a). Each bidder reports its costs to a proxy agent for all packages that the bidder is interested in supplying. The proxy agent then bids in a descending package auction on behalf of the real bidder, iteratively submitting the allowable bid that, if 
accepted, would maximize the real bidder's profit (price minus cost), based on the reported costs. The auction in theory is conducted with negligibly small bid decrements. After each round, provisionally winning bids are determined that minimize the buyer's cost from compatible bids. All of a bidder's bids are kept live throughout the auction and are treated as mutually exclusive. The auction ends after a round with no new bids (see Hoffman et al. 2006 and Day and Raghavan 2004 for practical methods to implement the proxy phase).

The advantage of this format is that it ends at a core allocation for the reported preferences. Denote the coalition form game $(L, w)$ where $L$ is the set of players ( $l=0$ is the buyer and the rest are the bidders) and $w(S)$ is the value of coalition $S$. Let $X$ denote the set of feasible allocations $\left(x_{l}\right)_{l \in L}$. If $S$ excludes the buyer, then $w(S)=0$; if $S$ includes the buyer, then

$$
w(S)=\max _{x \in X} \sum_{l \in S} v_{l}\left(x_{l}\right) .
$$

The Core $(L, w)$ is the set of all imputations $\pi$ (payoffs imputed to the players based on the allocation) that are feasible for the coalition of the whole and cannot be blocked by any coalition $S$; that is, for each coalition $S, \sum_{l \in S} \pi_{l}\left(x_{l}\right) \geq w(S)$.

Theorem (Ausubel and Milgrom 2002, Parkes and Ungar 2000). The payoff vector $\pi$ resulting from the proxy auction is a core imputation relative to the reported preferences: $\pi \in \operatorname{Core}(L, w)$.

Core outcomes exhibit a number of desirable properties, including: 1) efficiency, and 2) competitive revenues for the seller. Thus, the theorem shows that the proxy auction is not subject to the inefficiency of supply reduction: no bidder can ever reduce the price it pays for the package it wins by withholding some of its losing bids for other packages. The theorem also includes the idea that the seller earns competitive revenues: no bidder or coalition of bidders is willing to bid less to supply the buyer's goods. Ausubel and Milgrom (2002, Theorems 2 and 14) establish the core outcome result, whereas Parkes and Ungar (2000, Theorem 1) independently demonstrate the efficiency of outcomes of an ascending proxy auction without addressing the issue of the core.

A payoff vector in the core is said to be bidder optimal if there is no other core allocation that all bidders prefer. If the items are substitutes, then the outcome of the proxy auction coincides with the outcome of the Vickrey auction and with the unique bidder-optimal point in the core. If the goods are not substitutes, then the Vickrey payoff is not generally in the core and the proxy auction yields an outcome with lower buyer cost.

Theorem (Ausubel and Milgrom 2002). If $\pi$ is a bidder-optimal point in the Core $(L, w)$, then there exists a full-information Nash equilibrium of the proxy auction with associated payoff vector $\pi$.

These equilibria may be obtained using strategies of the form: bid your true cost plus a nonnegative constant on every package. We emphasize that this conclusion concerns full-information Nash equilibrium: bidders may need to know $\pi$ to compute their strategies. 
Two important advantages of the proxy auction over the Vickrey auction are that the prices and revenues are monotonic (increasing the set of bidders leads to lower prices) and the payoffs are competitive. See Ausubel and Milgrom (2006b).

Further details of the clock-proxy auction are described in Ausubel et al. (2006).

\section{Conclusion}

A simultaneous descending auction is a powerful tool to procure many related items. When the items are divisible goods, a clock auction format is best. The auctioneer announces a price for each good, and bidders express the quantities of goods that they wish to provide at the current prices. The prices of the goods are decremented in relation to their respective excess supply. The process repeats until there is no excess supply for any good. At that point bidders are awarded their quantities bid at the final prices.

While the underlying theory utilizes continuous clocks, bidding in real-world dynamic auctions normally occurs in discrete rounds. This, however, does not pose much of an obstacle to efficiency. What is needed is a mechanism for bidders in each round to express supply at intermediate prices between the starting and ending prices. This intra-round bidding enables the efficiency gains of continuous clocks. All that is lost is the withinround price discovery, but this is much less important than the price discovery between rounds, which is retained — and even enhanced_-by a pause in the bidding, allowing time for the bidders to update their strategies in light of the new information.

An important element of the auction design is the activity rule, which limits bidding behavior in a way that is consistent with reasonable economic incentives. This promotes price discovery. In clock auctions for a single good, all that is required is a monotonicity condition: as prices fall, bidders can maintain the same quantity or reduce quantity, but cannot increase quantity. Thus, the bidding must be consistent with an upward-sloping supply curve. With many goods that are close substitutes, such a condition would be excessively harsh. In such auctions, it is best to group goods together that are strong substitutes and impose the monotonicity on the bidder's total quantity within the group. This enables bidders to arbitrage freely across goods within the group. Buyer substitution also can be addressed. For example, the buyer can specify price spreads across goods in a group and only specify the total quantity for the group. The quantity procured of each good within a group is then determined by both the suppliers' and buyer's preferences.

Market power is a final practical concern. This is addressed with three instruments available to the auctioneer. An information policy is established to limit the bidders' ability to adopt collusive strategies. Reserve prices and demand adjustments are used to limit the incentive for collusion and to guarantee reasonable procurement costs even if competition is weak or collusion is effective. Finally, the buyer can switch from uniform pricing to Vickrey pricing to avoid the inefficiencies created by market power under uniform pricing. When combined properly these three tools can address both the efficiency and procurement cost increases arising from market power.

Although simultaneous clock auctions are new, they have already been applied in high-stakes auctions in many countries. Applications have included electricity auctions in France, the US and Belgium, gas auctions in Germany, France and Austria, and environmental auctions in the UK. 
For highly competitive auctions of items that are mostly substitutes, a simultaneous clock auction will perform well. Indeed a simultaneous clock auction may be the best approach, as it offers the greatest simplicity and transparency, while being highly efficient.

For more complex environments, we recommend the clock-proxy auction-a simultaneous clock auction followed by a last-and-final proxy round. The basic idea is to use anonymous linear prices as long as possible to maximize price discovery, simplicity, and transparency. The clock phase also greatly facilitates the bidders' cost analysis for the proxy round, because the analysis can be confined to the relevant part of the price space identified in the clock phase. Finally, unlike the simultaneous descending auction, the clock auction does not suffer from the exposure problem.

With limited competition or items with a complex and varied structure of complements, adding the proxy phase can improve the auction outcome. In particular, a core outcome is achieved. Buyer procurement costs are competitive and the allocation is efficient. The supply reduction incentive present in the clock phase is eliminated. Most importantly, adding the proxy round does no harm: in the simplest settings where the clock auction alone performs well, adding the proxy round should not distort the outcome. The proxy round simply expands the settings in which the auction performs well.

\section{References}

Ausubel, Lawrence M. (2004), “An Efficient Ascending-Bid Auction for Multiple Objects,” American Economic Review, 94:5, 1452-1475.

Ausubel, Lawrence M. (2006), “An Efficient Dynamic Auction for Heterogeneous Commodities,” American Economic Review, forthcoming.

Ausubel, Lawrence M. and Peter Cramton (2002), “Demand Reduction and Inefficiency in Multi-Unit Auctions,” University of Maryland Working Paper 96-07.

Ausubel, Lawrence M. and Peter Cramton (2004a), “Auctioning Many Divisible Goods,” Journal of the European Economic Association, 2, 480-493, April-May.

Ausubel, Lawrence M. and Peter Cramton (2004b), “Vickrey Auctions with Reserve Pricing,” Economic Theory, 23, 493505.

Ausubel, Lawrence M. Peter C. Cramton and Wynne P. Jones (2002), "System and Method for an Auction of Multiple Types of Items,” International Patent Application No. PCT/US02/16937.

Ausubel, Lawrence M., Peter Cramton, and Paul Milgrom (2006), “The Clock-Proxy Auction: A Practical Combinatorial Auction Design," in Peter Cramton, Yoav Shoham, and Richard Steinberg (eds.), Combinatorial Auctions, Chapter 5, 115-138, MIT Press.

Ausubel, Lawrence M. and Paul Milgrom (2002), “Ascending Auctions with Package Bidding,” Frontiers of Theoretical Economics, 1: 1-45, www.bepress.com/bejte/frontiers/vol1/iss1/art1.

Ausubel, Lawrence M. and Paul Milgrom (2006a), “Ascending Proxy Auctions,” in Peter Cramton, Yoav Shoham, and Richard Steinberg (eds.), Combinatorial Auctions, Chapter 3, 79-98, MIT Press.

Ausubel, Lawrence M. and Paul Milgrom (2006b), “The Lovely but Lonely Vickrey Auction,” in Peter Cramton, Yoav Shoham, and Richard Steinberg (eds.), Combinatorial Auctions, Chapter 1, 17-40, MIT Press.

Brusco, Sandro and Giuseppe Lopomo (2002), “Collusion via Signalling in Simultaneous Ascending Bid Auctions with Heterogeneous Objects, with and without Complementarities,” Review of Economic Studies, 69, 407-436.

Compte, Olivier and Philippe Jehiel (2002), “Auctions and Information Acquisition: Sealed-bid or Dynamic Formats?” Working Paper, CERAS-ENPC. 
Cramton, Peter (1997), “The FCC Spectrum Auctions: An Early Assessment,” Journal of Economics and Management Strategy, 6:3, 431-495.

Cramton, Peter (2006), “Simultaneous Ascending Auctions,” in Peter Cramton, Yoav Shoham, and Richard Steinberg (eds.), Combinatorial Auctions, Chapter 4, 99-114, MIT Press.

Cramton, Peter and Jesse Schwartz (2002), "Collusive Bidding in the FCC Spectrum Auctions," Contributions to Economic Analysis \& Policy, 1:1, www.bepress.com/bejeap/contributions/vol1/iss1/art11.

Cramton, Peter, Yoav Shoham, and Richard Steinberg (2006), Combinatorial Auctions, Cambridge, MA: MIT Press.

Day, Robert W. and S. Raghavan (2004), "Generation and Selection of Core Outcomes in Sealed-Bid Combinatorial Auctions,” Working Paper, University of Maryland.

Grimm, Veronika, Frank Riedel, Elmar Wolfstetter (2002), "Low price equilibrium in multi-unit auctions: the GSM spectrum auction in Germany,” International Journal of Industrial Organization, 21, 1557-1569.

Hoffman, Karla, Dinesh Menon, Susara van den Heever, Thomas Wilson (2006), "Observations and Near-Direct Implementations of the Ascending Proxy Auction,” in Peter Cramton, Yoav Shoham, and Richard Steinberg (eds.), Combinatorial Auctions, Chapter 17, 415-450, MIT Press.

Laan, Gerard van der and A.J.J. Talman (1987), “Adjustment Processes for Finding Economic Equilibria,” in A.J.J. Talman and Gerard van der Laan, eds., The Computation and Modelling of Economic Equilibria, Amsterdam: North-Holland, 85-124.

McAdams, David (2005), “Adjustable Supply in Uniform Price Auctions: The Value of Non-Commitment,” Working Paper, MIT.

Milgrom, Paul (2004), Putting Auction Theory to Work, Cambridge: Cambridge University Press.

Milgrom, Paul and Robert J. Weber (1982), “A Theory of Auctions and Competitive Bidding,” Econometrica, 50, 10891122.

Parkes, David C. and Lyle H. Ungar (2000), “Iterative Combinatorial Auctions: Theory and Practice,” Proceedings of the 17th National Conference on Artificial Intelligence (AAAI-00), 74-81.

Porter, David, Stephen Rassenti, Anil Roopnarine, and Vernon Smith (2003), “Combinatorial Auction Design,” Preceedings of the National Academy of Sciences, 100, 11153-11157.

Samuelson, Paul A. (1941), "The Stability of Equilibrium: Comparative Statics and Dynamics," Econometrica, 9, 97-120.

Varian, Hal R. (1981), "Dynamical Systems with Applications to Economics," in Kenneth J. Arrow and Michael D. Intriligator, eds., Handbook of Mathematical Economics, Volume I, Amsterdam: North-Holland, chapter 3.

Vickrey, William (1961), “Counterspeculation, Auctions, and Competitive Sealed Tenders,” Journal of Finance, 16, 8-37. Walras, Léon (1874), Éléments d'Économie Politique Pure, Lausanne: Corbaz. 